\title{
FDG-PET Scanning Finding
}

National Cancer Institute

\section{Source}

National Cancer Institute. FDG-PET Scanning Finding. NCI Thesaurus. Code C116094.

A nuclear medicine finding obtained using FDG-PET imaging technique. 